\title{
THEODOR ADORNO Y EL PROBLEMA DE LA RACIONALIDAD MODERNA: ARISTAS GERMINALES DE UNA INQUIETUD CRÍTICA
}

\author{
Theodore Adorno and the problem of modern rationality: germinal edges of a \\ critical concern
}

\section{RESUMEN}

El pensamiento de Theodor Adorno sitúa el núcleo de sus preocupaciones en el terreno de la modernidad europea. La textura entera de sus reflexiones brinda múltiples huellas y abre diversas vías a partir de las cuales acercarse al fenómeno denominado «modernidad» como tiempo histórico caracterizado por las contradicciones decisivas de un estado de la cultura y la sociedad. Por eso, en el marco de las críticas materialistas a la racionalidad moderna, la filosofía adorniana destaca por su relevancia.

Así entonces, el objetivo de este escrito consiste en indagar la cartografía de las distintas vertientes teóricas que definen la actividad filosófica de Alemania en las primeras décadas del siglo XX efectuada por este pensador con el fin de advertir la diagnosis que orienta sus reflexiones. Comprender el modo en que Adorno interpreta el estado de la racionalidad filosófica en los albores del siglo XX constituye un momento insoslayable a la hora de capturar algunas de las preocupaciones fundamentales de su pensamiento en torno a la modernidad.

Palabras claves: Theodor Adorno; modernidad; crítica; razón; racionalidad filosófica

\section{UNIVERSUM}

Revista de Humanidades y Ciencias Sociales

\section{MARÍA RITA MORENO}

becaria posdoctoral de CONICET en el Instituto de Ciencias Sociales, Humanas y Ambientales del Centro Científico-Tecnológico de Mendoza; es Doctora en Filosofía por la

Facultad de Filosofía y Letras de la UNCuyo y docente de la UNCuyo.

Correo electrónico: xrmkmx@gmail.com;

mmoreno@mendoza-conicet-gob.ar

ORCID: 0000-0002-0858-4077

ResearchGate:

Scholar.google:

Academia.edu:

Artículo recibido el 3 de marzo, 2020. Aceptado el 4 de junio, 2020.

DOI:

Web: http://universum.utalca.cl | ISSN: 0716-498X - 0718-2376 


\begin{abstract}
:
Theodor Adorno's thinking places the core of his concerns in the field of European modernity. The entire texture of his reflections offers several traces and opens up different paths from which to approach the complex called «modernity», understood as a historical time characterized by crucial contradictions of a state of culture and society. For this reason, among the materialistic criticism of modern rationality, stands out Adorno's philosophy for its relevance.

Thus, the aim of this paper is to research the cartography of the different theoretical aspects that define the philosophical activity of Germany during the first decades of the 20th century carried out by this thinker in order to make a diagnosis to guide his reflections. Understanding how Adorno interprets the state of philosophical rationality at the dawn of the 20th century constitutes an unavoidable moment when it comes to capturing some of the fundamental concerns of his thought modernity.
\end{abstract}

Key words: Theodor Adorno; modernity; reason; critique; philosophical rationality

1. El pensamiento de Theodor W. Adorno asume como el perímetro de sus preocupaciones el terreno establecido por la modernidad europea. En tanto que "la modernidad es lo transitorio, lo fugitivo" (Benjamin, 2005: 256 [ $\mathrm{J} 6 \mathrm{a}, 3]$ ), el norte de sus inquietudes aparece en sus textos cifrado por "la determinación cualitativa de la modernidad" (Adorno, 2004: 403). Según entiende este pensador, la modernidad constituye un tiempo histórico caracterizado por contradicciones en el despliegue de la razón a partir de las cuales el dominio de la verdad ha devenido al inicio del siglo XX en una instancia trágica y problemática: la tragedia de esta época se muestra en la forma de una imposibilidad absoluta para dar solución a sus conflictos internos y para ejecutar la exploración racional de lo real. En este sentido, el célebre inicio de Teoría Estética que declara que "ha llegado a ser obvio que ya no es obvio nada que tenga que ver con el arte" (Adorno, 2004: 9) 
puede ser leído extensivamente como la sentencia categórica que indica el deterioro generalizado de la racionalidad moderna: Adorno detecta que los ejes enunciados por la modernidad europea definen un territorio en el que ni el conocimiento racional ni la verdad resultan obvios.

Este diagnóstico adorniano emerge fruto del diálogo con otras reflexiones que configuran la atmósfera de su época. Entre ellas, pueden identificarse ejes temáticos y conceptuales a partir de los cuales el filósofo nutre su propia teoría, así como también, posturas con las que polemiza de manera expresa. Sin embargo, todas ellas intervienen en el modo en que Adorno da forma a su crítica.

Responder de qué manera específica modula Adorno las contradicciones de la racionalidad en las condiciones contemporáneas de la modernidad demanda, como puede preverse, un trabajo titánico puesto que el filósofo dedica gran parte de su prolífica obra a este tema. No obstante, sí es factible en el marco de este escrito abordar algunas de las aristas germinales de esta crítica. Así entonces, nos proponemos indagar el modo en que Theodor Adorno interpreta el escenario de la racionalidad filosófica en los albores del siglo XX con el fin de comprender la diagnosis que orienta sus posteriores reflexiones. Para ello, consideramos fundamental atender de manera especial las evaluaciones que Adorno realiza de las expresiones filosóficas más significativas de su época, pues ellas constituyen un momento ineludible a la hora de capturar algunas de las preocupaciones fundamentales del filósofo.

2. Dentro del entramado de críticas a la racionalidad moderna, puede mencionarse la llevada a cabo en Historia y conciencia de clase, texto publicado en 1923. Allí Georg Lukács explica que la modernidad se caracteriza por un proceso de creciente racionalización (2013: 193). Este ha decantado no solo en la progresiva eliminación de las propiedades cualitativas e individuales del trabajador, sino, además, en la descomposición del proceso de trabajo en diversas operaciones parciales abstractamente racionales. De esta manera, en lo que respecta al ámbito del conocimiento, lo definitorio del quehacer intelectual de la época moderna radica en la especialización científica. Así, 
la división social del trabajo resuelve una más precisa delimitación de las disciplinas y, con ello, una sólida soberanía sobre sus objetos de estudio. Lukács sostiene que todo este proceso de especialización de la razón encuentra en el principio del cálculo la pilastra donde afirmarse: "la racionalización basada en la calculabilidad" determina las transformaciones que "se producen en el sujeto y el objeto del proceso económico" (Ibidem: 193). En consecuencia, según el filósofo húngaro, la razón moderna configurada bajo el régimen del principio de calculabilidad "va perdiendo cada vez más intensamente su carácter mismo de actividad, para convertirse paulatinamente en una actitud contemplativa" (Ibidem: 195).

Por otro lado, hacia 1946, unos veinte años más tarde, Max Horkheimer inicia su Crítica de la razón instrumental caracterizando una razón subjetiva y una razón de carácter objetivo. Mientras que la última — propia del mundo clásico - aspira a establecer un sistema vasto de todo lo vinculado al hombre en relación a fines, la concepción subjetivista de la razón privilegia el pensamiento antes que el pensar: la teoría moderna se instrumentaliza a sí misma en la medida en que la "«razón» se utiliza más bien para designar una cosa o un pensamiento y no un acto" (Horkheimer, 2007: 17). El énfasis puesto sobre los medios y no ya sobre los fines, característico de la racionalidad subjetivista de la modernidad, conduce a una "actual crisis de la razón" (Ibidem: 18) a causa de la cual ninguna realidad puede aparecer como objetiva ni racional. Por eso "al subjetivizarse, la razón también se formaliza" (Ibidem: 19), y así la actividad filosófica se vacía de sentido, pues pierde sentido incluso el concepto de «verdad».

De esta manera, dos filósofos paradigmáticos dentro de la filosofía materialista de principios de siglo XX indican — cada cual a su manera- que la retirada del sujeto hacia la contemplación instrumental y el cálculo muestran "al pensamiento burgués moderno como algo que se encuentra en un impasse, embarrancado y paralizado en una pasividad terminal" (Said, 2015: 18). Tanto Lukács como Horkheimer acogen dentro del derrotero de sus reflexiones la situación problemática que se cernía sobre la actividad del pensar en las primeras décadas del siglo XX. Ambos momentos forman parte de una compleja trama 
hilvanada a partir de las elaboraciones de la filosofía materialista en torno al problema de la razón moderna. Esta trama recorre la dialéctica implicada en los logros asociados a la salida de «la autoculpable minoría de edad» (Kant, 2010) - la veta expansiva de la modernidad europea - y su neutralización con la pérdida del sentido asociada al «desencantamiento del mundo» (Weber, 2001) —el movimiento contractivo de esa misma modernidad-.

La falta de un sentido inmanente, percibida como una patente disgregación de las esferas de lo social, fue traducida de diversas maneras según los ámbitos donde se afincara la reflexión, pero todas ellas apuntaban a la destrucción del sentido social dado por el enfrentamiento entre el yo y las fuerzas totales (cultura subjetiva/cultura objetiva, pulsiones/restricciones culturales): al «desencantamiento del mundo» en lenguaje weberiano se suman diagnósticos tales como el de Georg Simmel acuñado en la expresión «tragedia de la cultura» (2011), la declaración de una «decadencia de Occidente» en palabras de Oswald Spengler (1993), e incluso el dictamen freudiano del «malestar en la cultura» (2007).

En la trama de estas críticas a la razón - y, específicamente, en el marco de las críticas materialistas a la racionalidad moderna- emerge con especial contundencia la elaborada por Theodor Adorno ya que, como ha señalado Albrecht Wellmer (2013: 165), este filósofo dedicó una gruesa parte de su obra a la tarea crítica de una «metahistoria» de la razón.

¿De qué manera se modula en la filosofía adorniana la crítica al devenir de la racionalidad moderna? Situar sus disquisiciones en torno a esta cuestión en el diagnóstico de época que aqueja por entero al pensamiento de las primeras décadas del siglo XX constituye solo un primer paso a fin de comprender algunas de sus características más particulares. Incluso, en medio del arco tejido entre la caracterización de la razón indicada por Georg Lukács y Max Horkheimer, Adorno representa el ejercicio de una atenta lectura de los aportes de Lukács ${ }^{1}$ tanto como la colaboración —no siempre congruente-

1 Adorno rescató y potenció algunos de los elementos más fecundos de la filosofía lukacsiana. Asimismo, consideró muy severamente otros. Cfr. La idea de historia natural y Reconciliación extorsionada, como muestras de ambos polos. 
con Horkheimer².

Por supuesto que la figura de Adorno no puede considerarse un mero eslabón intermedio. Lejos de esta imagen se sitúa la reflexión que aquí proponemos. Más precisamente, pretendemos detener nuestra búsqueda en algunos momentos de la filosofía adorniana con el objetivo de discernir ciertos elementos relevantes en relación a su crítica de la razón moderna.

3. Theodor Adorno advierte que, en el marco de la modernidad de principios de siglo $\mathrm{XX}$, la filosofía no constituye una actividad evidente en sí misma. El filósofo frankfurtiano percibe el proceso de embotamiento de la razón y es sumamente sensible a él: "el arsenal conceptual de la filosofía moderna ya no alcanza para comprender el alcance de su crisis" (Foster, 2014: 14). De allí que los caminos filosóficos se muestren completamente obliterados, pues entre "la delectación en el vacío" - promovida por el irracionalismo"y la promesa de la abundancia" — perpetrada por las distintas versiones del positivismo- "la clase dominante del espíritu no admite ningún tercero" (Adorno, 2006: 73).

Desde el punto de vista de Adorno, la filosofía ha alcanzado en los siglos precedentes —especialmente en Alemania - un rigor sistémico y reflexivo cuya culminación se identifica con el pensamiento hegeliano. Sin embargo, esas conquistas especulativas han sido posteriormente cuestionadas con vehemencia. En un comienzo, el siglo que fue testigo de la Revolución Industrial dio a luz las elaboraciones conceptuales más contundentes. Ellas pretendieron denunciar los meollos del decurso en que se había desarrollado la humanidad mediante los materiales - concepto, juicio y razonamiento- y fundamentos —el valor inapelable de «lo verdadero», por ejemplo- que la filosofía había construido durante siglos. Karl Marx y Friedrich Nietzsche consolidaron de manera paradigmática las más fuertes críticas aún en el marco de una racionalidad conceptual, extrayendo de ella las herramientas

2 Dialéctica de la Ilustración y Hacia un nuevo manifiesto son, respectivamente, ejemplos del trabajo mancomunado y de las distancias que zanjaron la relación entre Adorno y Horkheimer. 
para discernir las condiciones de un mundo mejor.

No obstante, el cambio de siglo al que se enfrentó Adorno trajo consigo una invectiva de muy otra especie que dirigía sus ataques hacia el nervio vital mismo de la filosofía. Ya no se trataba, como en el ejercicio teórico de Marx o de Nietzsche, de objetar las categorías o conclusiones de una propuesta filosófica desde la filosofía misma. La causa de ello se encontraba en que dos de los puntos más álgidos de la modernidad filosófica habían conducido a senderos que, de una manera u otra, anulaban la plasticidad del pensamiento filosófico.

En primer lugar, en el primer tramo de la modernidad, el sistema crítico kantiano logró discernir los límites determinados dentro de los cuales le estaba permitido al intelecto hacer filosofía legítimamente. A pesar de que la intención del filósofo ilustrado consistía en potenciar el pensamiento filosófico mediante la correcta localización de su área de incumbencia, la publicación en 1921 del Tractatus logico-philosophicus pintó por entero el talante de algunas de sus posibles consecuencias: "de lo que no se puede hablar, hay que callar" (Wittgenstein, 2009: 137) es, probablemente, uno de los dictámenes más severos con el que haya tenido que lidiar la filosofía. Él declaraba el único destino admisible para la filosofía en el escenario de emergencia del pensamiento adorniano: "no decir nada más que lo que se puede decir, o sea, proposiciones de la ciencia natural —o sea, algo que nada tiene que ver con la filosofía_-" (Ibidem: 137). Así pues, la modernidad devenida en el siglo XX suponía no ya la demarcación de la legitimidad del concepto filosófico, sino más bien su conminación al silencio.

Según comprende Adorno, la lanza del Círculo de Viena impugnaba directamente la pretensión de verdad del pensamiento filosófico y, con ello, la legitimidad de su existencia. Si se le concedía sobrevivir, la filosofía debía abandonar cualquier ambición sistémica, pues la lógica formal la evidenciaba en sus ínfulas impotentes de ordenación de todo el conocimiento. Empero, y como consecuencia de lo anterior, la racionalidad filosófica debía renunciar también a las preocupaciones que tradicionalmente consumían sus esfuerzos.

Adorno advierte, entonces, que ante el desmoronamiento de la 
Weltanschauung burguesa, las palabras científico-filosóficas que explicaban ese desplome parecían no tener la habilidad para reconstruir nuevos sentidos. La filosofía retrocedía ante el avance de la lógica formal al tiempo que sus preocupaciones clásicas se desplazaban al ámbito de las nuevas ciencias sociales, las cuales los codificaban según sus propias lógicas y métodos. La dinámica lineal de la palabra y la potencia de los conceptos perdían la contundencia que las había caracterizado: el famoso texto de Lord Chandos, escrito por Hugo von Hofmannsthal justo en el inicio del siglo XX, puede considerarse en este sentido sintomático. ${ }^{3}$

En segunda instancia, otra de las cumbres en que la filosofía moderna estatuyó un monumento a su poder se encontraba en la filosofía hegeliana. Empero,Adorno interpreta que, en relación a las derivas de la dialéctica incubada por Hegel y proseguida de manera divergente por Marx, el mutismo teórico había transmutado en baldo mecanicista. El camino hacia el conocimiento y la concreción del contenido y su devenir, objetivo fundante de la filosofía hegeliana, se vio obturado cuando la forma del sistema se hipostasió. Las enmiendas de intenciones revolucionarias expresadas en la teoría del reflejo o las adjudicaciones partidarias de una conciencia revolucionaria, ${ }^{4}$ entre otras, aludían la incapacidad de comprender ciertos procesos a la vez que evidenciaban los costados más flacos del materialismo dialéctico. Así entonces, las acusaciones neopositivistas cobraban vigor. Las diferentes indagaciones de los miembros del Círculo de Viena coincidían en la ineptitud creativa de la filosofía: a ella se le permitía seguir con vida solo si purgaba con su pena

3 En La carta de Lord Chandos, Hugo von Hofmannsthal (1902) escribe "Mi caso, para ser breve, es éste: he perdido completamente la facultad de reflexionar o hablar en forma coherente sobre un tema cualquiera (...) Experimentaba una sensación de malestar inexplicable ante la necesidad de pronunciar las palabras "espíritu", "alma" o "cuerpo". (...) sucedía que las palabras abstractas a las cuales, sin embargo, ha de recurrir la lengua a fin de poder formular el más intrascendente juicio valorativo, literalmente se me pulverizaban en la boca, como si fueran hongos podridos".

4 Las afirmaciones en torno al rol salvífico del Partido en la lucha de clases y la imputación de una conciencia proletaria a la clase trabajadora se cuentan entre aquellos puntos de la teoría lukacsiana más discutidos por Adorno. 
semántica y aceptaba la reclusión expectante en el mundo lógico-matemático.

Ahora bien, en la medida en que la exaltación de la racionalidad matemática y/o sistémica conducía a la aparente aporía filosófica, la indagación irracionalista se configuraba consecuentemente en una redentora red de contención. Así entonces, si el positivismo en sus distintas variantes conminaba a la quietud observante, la filosofía encontró el modo de arrancarse el bozal configurando un área de compleja soberanía disciplinar: la filosofía pretendió convertirse en la especialista del irracionalismo.

El título impreciso de lo irracional, cuyo más importante representante halla Adorno en Henri Bergson (Adorno, 2013: 95), agrupa a las filosofías que en lo fundamental conciben el conocimiento intelectual como algo externo a sus objetos en la medida que dice demasiado poco de la vida de la cosa misma. Son las filosofías que sacrifican los "criterios de lo controlable, de la necesidad y de la universalidad que la ciencia occidental, desde sus inicios cartesianos, convirtió en sus criterios superiores" (Ibidem: 96). El psicoanálisis gestado por Sigmund Freud, el relativismo supuesto en algunas expresiones de la filosofía francesa (alentadas precisamente por algunos de los aportes de Bergson) e incluso algunas secuelas de las filosofías de Schopenhauer y Nietzsche dieron paso a la exaltación de lo efímero, el enarbolamiento de lo disgregado y la supremacía de las emociones.

Las tentativas de diagramar diversos horizontes tanto como las interpretaciones que intentaban explicar ese presente constituían un escenario disciplinar complicado. La filosofía no solo se hallaba cuestionada en su licitud misma sino incluso, evidenciada en la impotencia de doblegar semejante afrenta. ¿Cuáles eran, en consecuencia, las vías teóricas habilitadas para Theodor Adorno, un pensador enlazado de manera significativa tanto con la teoría kantiana como con la dialéctica hegeliano-marxista?

El filósofo se enfrentó no solo a las crisis políticas y económicas de su región sino también al derrumbamiento del clásico poder inquisitivo de la filosofía. El origen de las reflexiones adornianas más densas en relación a la racionalidad moderna se vio empapado en sus basamentos mismos por esta proclamada impotencia de la filosofía. Frente al panorama descrito, Theodor 
Adorno consiguió empero leer novedosamente y posicionarse de manera particular. Ahora bien ¿de qué manera articuló ad intra, es decir, teóricamente, este trabajo?

4. A fin de responder tal pregunta, resulta pertinente acudir también a algunas polémicas filosóficas presentes en la filosofía de Adorno y rescatar en ellas ciertos elementos que permitan comprender la particular crítica adorniana a las contradicciones de la racionalidad moderna.

En esa dirección, cabe mencionar que para algunos de los exponentes del materialismo histórico (sobre todo aquellos comprometidos con el proyecto soviético), la recuperación de la totalidad como horizonte del pensamiento y de la política se había tornado una tarea básica. El ya mencionado Lukács, por ejemplo. El pensador húngaro constituye quizás el paradigma del filósofo materialista con el que las reflexiones de Adorno dialogan más o menos explícitamente. La perspectiva lukacsiana entiende el desmembramiento del todo social como resultado negativo de relaciones sociales contradictorias. La desarticulación social característica de la Europa pos-Industrial es leída como la evidencia de una sociedad escindida cuyas relaciones han sido moldeadas según la esencia de la sociedad capitalista y su presupuesto fundamental, "la división capitalista del trabajo" (Lukács, 2013: 211).

Así, su teoría materialista concentra su preocupación en engarzar sus reflexiones con la práctica política cotidiana, por eso ve en la división del trabajo el principio problemático por antonomasia; le adjudica como unas de sus consecuencias más patentes y nefastas la destrucción de todo proceso orgánico y unitario del trabajo y de la vida como también la especialización no solo de los roles sociales, sino incluso del pensamiento. Es decir, tanto el desgarramiento de la unidad entre teoría y praxis como la contraposición de posibilidades técnicas y estado general de la cultura encuentran su fundamento último en el ordenamiento capitalista de la vida.

Adorno comprende también que la estructuración de la edad moderna responde al decurso dialéctico de la historia y acuerda que la división social del trabajo aparece como una realidad innegable. Empero, mientras que para 
algunos representantes del materialismo dialéctico aquella división constituye la dificultad elemental (ya que la especialización a nivel teórico produce un conocimiento fragmentario el cual impide a los intelectuales y a los trabajadores ver a través de las apariencias reificadas de la realidad), Adorno hace hincapié en el carácter ineludible de esas condiciones históricas. Él no apunta a encontrar la clave para reconciliar tal disgregación en su potencial unidad; sino, por el contrario, a enfrentarse a las condiciones materiales concretas para extraer de ellas, con actitud dialéctica, el contenido histórico y desplegarlo en su verdad.

La estrategia crítica de Adorno consiste, entonces, en exprimir la potencia propia de los fragmentos resultantes de la disgregación antes que la construcción de una unidad conciliatoria de la disolución. Mientras que, ante las contradicciones modernas materializadas en el desmembramiento de las esferas sociales, una arteria del materialismo dialéctico enfatiza la totalidad, Adorno ejecuta un movimiento intensivo frente al mismo fenómeno: exprimir cada uno de los segmentos hasta hacerlo decir algo nuevo. En consecuencia, la disgregación de la filosofía respecto de los otros ámbitos del saber desplaza su registro y comienza a ser interpretada bajo la rúbrica de lo disperso, lo fragmentario advertido en su autonomía; ella es capaz de desplegar otros contenidos y otras formas a partir de su relación mediada con la praxis.

¿Cómo logra fundamentar esto? En Historiay conciencia declase Lukács muestra que la estructura cosificada de la conciencia configura los sentidos del mundo moderno. El pensador húngaro logra demostrar que "el problema estructural central de la sociedad capitalista en todas sus manifestaciones vitales [es] el problema de la mercancía" (Lukács, 2013: 187). Con ello logra descubrir en la estructura de la relación mercantil no solo el prototipo de todas las formas de objetividad, sino aún más, el prototipo de todas las correspondientes formas de subjetividad propias de la sociedad burguesa. La estructura de la mercancía no es, según su análisis, una forma entre muchas de intercambio social entre los hombres, sino la forma universal de configuración social mediante la que se explica también el estado actual de la cultura. 
La consecuencia directa que Lukács extrae de ello es la inmediata necesidad de combatir los productos de la división social del trabajo con la labor aunada de las esferas en que la sociedad había devenido: artista, intelectual y político unificarían sus esfuerzos con los intereses de la clase revolucionaria a fin de concretar la transformación de las condiciones de existencia de la humanidad.

Adorno trabaja de un modo muy especial sobre esta ecuación; sustrae de ella, no obstante, un resultado por entero diferente al del filósofo húngaro. Él toma el análisis lucaksiano para confirmar sus premisas (Buck-Morss, 2011: 100): la tradición intelectual burguesa está evidentemente configurada en todas sus manifestaciones por la estructura mercantil del modo capitalista de producción. Ello significa, empero, que, en cuanto productos históricos de un modo de ordenamiento específico, gozan de un momento de verdad: su contenido y su forma están atravesados en sí mismos por los problemas sociales. La racionalidad filosófica, aún en su embotamiento histórico, expresa, entonces, los antagonismos de la estructura social.

En consecuencia, aunque el desglose de lo social clausura la pretensión tradicional de la filosofía de sistematizar el todo desde el punto de vista de la unidad, no obstante, abre una nueva posibilidad, la de concentrarse en las minucias disgregadas para destapar en ellas, con «mirada micrológica», el complejo funcionamiento de la dialéctica histórica. Dice Adorno:

los más mínimos rasgos intramundanos tendrían relevancia para lo absoluto, pues la mirada micrológica rompe las cáscaras de lo, según la pauta del concepto genérico subsumidor, desamparadamente singularizado y hace estallar su identidad, el engaño de que sería meramente un ejemplar. (Adorno, 2005: 373).

La singularidad de la mirada benjaminiana en relación a los detalles y las miniaturas señala en la misma dirección: "así como la majestad de los mosaicos permanece inalterada cuando estos se fragmentan en pequeñas partes caprichosas, del mismo modo la contemplación filosófica no padece menoscabo en el impulso. Ambos se componen a partir de lo individual y disperso" (Benjamin, 2012: 62). Tanto Benjamin como Wiesengrund ponen en valor el rol decisivo de los fragmentos para el pensamiento filosófico, ya que 
"el contenido de verdad solo puede ser captado sumergiéndose con la mayor exactitud en los detalles de un contenido objetivo" (Ibidem: 63). Ahora bien, ¿en qué sentido la insistencia en el trozo de realidad no reconciliado abre una veta fecunda para comprender la intrincada racionalidad moderna?

5. La lectura que orienta la perspectiva teórica de Adorno, apoyada en una conciencia de este modo definida de la coyuntura histórica e intelectual que lo convoca, comienza a gestarse desde temprano en base a una recurrente inquietud: la de la fundamentación temporal de todo ejercicio reflexivo. Lo que se dice aquí no podría sorprender a nadie. La filosofía de la historia que sostenía el gigantesco edificio del sistema hegeliano, por ejemplo, es sin duda el horizonte siempre presente en sus discusiones. ${ }^{5}$ No obstante, es esa misma configuración del desarrollo histórico la que es puesta en cuestión. La progresión del despliegue histórico en que la dialéctica idealista y la dialéctica materialista afluían constituye otro de los frentes con los que Adorno polemiza y en medio del cual despunta su ingenio filosófico. ${ }^{6}$

Para acercarnos al corazón del interés específico que cimenta la filosofía adorniana desde sus inicios, resulta oportuno recortar una expresión de Walter Benjamin — figura clave para comprender algunas zonas de la filosofía adorniana - en la que se expresa una específica interrelación de verdad y tiempo contenida en el fragmento:

5 A este respecto, basta con mencionar textos tales como Tres estudios sobre Hegel (1963) o "Espíritu del mundo e historia de la naturaleza. Excurso sobre Hegel" - el segundo modelo de la Dialéctica Negativa (1966) - tanto como algunos cursos ofrecidos por Adorno -Introducción a la dialéctica (1958) o Sobre la teoría de la historia y la libertad (19641965)-.

6 A la hora de indagar en la crítica a la lógica progresiva de la historia los aportes de Walter Bejamin son señeros. Sin embargo, Adorno, confesamente influenciado por algunos tópicos benjaminianos, se ocupa de este tema más o menos expresamente. $C f r$., por ejemplo, el ya referido curso de 1964-1965 Sobre la teoría de la historia y la libertad o la conferencia de octubre de 1962 titulada, justamente, Progreso. 
Hay que apartarse decididamente del concepto de «verdad atemporal». Sin embargo, la verdad no es - como afirma el marxismo - únicamente una función temporal del proceso de conocimiento, sino que está unida a un núcleo temporal, escondido a la vez tanto en lo conocido como en el conocedor. Tan verdadero es esto, que lo eterno es en todo caso más bien el volante de un vestido, que una idea." (Benjamin, 2005: $465[$ N 3, 2]).

La indagación del determinado vínculo de pensamiento y tiempo no acontece para Adorno concibiendo al primero como resultante del segundo. Tampoco identificando el despliegue de la historia con un metarrelato ordenador de las distintas manifestaciones del pensamiento. Por el contrario, Adorno pretende situarse en el meollo del fraccionamiento social, el del abismo tejido por el despliegue de la modernidad, para desde allí indagar la vertiginosa dialéctica que lo sostiene.

Esta tarea no se concreta, claro está, en un tris. La cadencia de su compleja composición solo emerge en la sintonía interpretativa de múltiples textos. Segmentar de manera definitiva el perímetro textual dentro del que se inscribe la filosofía de la historia que sostiene las reflexiones de Adorno sería injusto por impreciso. Lo cierto es que el lazo de verdad y tiempo urdido en sus reflexiones es tan definitivo y complejo que puede ser rastreado prácticamente en todas y cada una de sus obras.

No obstante, un acceso elocuente al vínculo verdad-tiempo presente en el fragmento desarticulado de un todo tal y como es pensado en la filosofía adorniana puede encontrarse en la temprana interpretación del escenario filosófico puesta de manifiesto con claridad en una conferencia pronunciada por el filósofo frankfurtiano en la década del 30.

De hecho, 1931 es el año que ubica temporalmente no solo la asunción de la dirección del Instituto de Frankfurt por parte de Max Horkheimer, sino también el momento en que Theodor Adorno comienza a formar parte de la Facultad de Filosofía de Frankfurt. En ocasión de ello, tuvo a cargo el discurso inaugural para el cual eligió el título La actualidad de la Filosofía. «Actualidad» [Aktualität] es el concepto que guía a Adorno para esbozar un rápido diagnóstico sobre la situación de la filosofía alemana de su tiempo. 
El texto en cuestión inicia con la explicitación de la condición de la razón filosófica de comienzos de siglo XX:

Quien hoy elija por oficio el trabajo filosófico, ha de renunciar desde el comienzo mismo a la ilusión con que antes arrancaban los proyectos filosóficos: la de que sería posible aferrar la totalidad de lo real por la fuerza del pensamiento. Ninguna Razón legitimadora sabría volver a dar consigo misma en una realidad cuyo orden y configuración derrota cualquier pretensión de la Razón. (Adorno, 1991: 73).

En consecuencia, la insistencia en los añicos desmembrados mediante los que se patentiza la modernidad se fundamenta en una imposibilidad histórica: si hay algo que puede conformar el punto de partida de cualquier gesto que se pretenda racional y filosófico es el hecho de que la totalidad no puede ya aparecer en el horizonte de su quehacer. Esta primera oración constituye una declaración contundente porque manifiesta el núcleo decisivo de la crítica a la razón efectuada por Adorno: razón y realidad no pueden relacionarse ya mediante la forma de la totalidad.

El autor que había sistematizado filosóficamente por completo la totalidad es, sin duda, Hegel. Él había explicado en la introducción de su Fenomenología del Espiritu que

lo verdadero es el todo. Pero el todo es la esencia que se acaba y completa a través de su desarrollo. De lo absoluto ha de decirse que es, esencialmente, resultado, y que sólo al final es lo que es en verdad. (Hegel, 2015: 16-17)

Adorno entiende que esta afirmación hegeliana no sostiene la totalidad en cuanto un algo orgánico amalgamado a sí mismo y, en ese sentido, inarticulado y hostil al pensar analizante. Empero, Hegel defiende en ese postulado - que es el que está en la mira cuando Adorno declara la renuncia necesaria a la hora de hacer filosofía en el siglo XX - una totalidad concebida como el "compendio de toda mediación, es decir, el compendio de todos esos movimientos que deben llevarse a cabo para que los conceptos esenciales reciban su concepción" (Adorno, 2013: 64).

Este modo de comprender la totalidad supone algo que merece ser discutido: afirmar que lo verdadero es el todo implica necesariamente afirmar la identidad de sujeto y objeto. Hegel no afirma un todo sin fisuras, pero sí afirma 
una totalidad en cuanto instancia sumaria de todas las mediaciones mediante las cuales sujeto y objeto concuerdan (llegan a concordar, mejor dicho). De allí que resulte para él factible aseverar la correspondencia de totalidad y verdad. Sin embargo, como ya se dijo antes, la disgregación total del orden de lo real como el punto de partida de la reflexión expresa que la vinculación de razón y realidad se ha modificado y la identidad de sujeto y objeto pareciera ya no poder operar. Por eso Adorno advierte que a ninguna conciencia en general, dadas las condiciones históricas en las que se muestra el siglo XX, le es dado el todo. De allí que Adorno afirme que la filosofía hegeliana y los intentos filosóficos de su presente bifurcan su andar en el hecho clave del que debería partir toda filosofía contemporánea, aquel que asevera que el todo no se deja resolver en las puras determinaciones del pensar.

El rechazo sistemático a las especulaciones que toman la totalidad como supuesto, como culminación o como estructura es un vector que recorre las diversas reflexiones que Adorno ejecuta y que comienza a edificarse en función del desgarramiento de la identidad sujeto-objeto, razón-realidad. Conforme esta perspectiva de análisis, él se pregunta cuáles son las expresiones que, en su intento por inaugurar nuevos senderos, constituyen a mediados del siglo XX el campo de lo filosófico ¿Ellas se hacen cargo, acaso, de la imposibilidad histórica de recurrir a la totalidad como horizonte del quehacer filosófico?

Adorno reconstruye el escenario filosófico circundante citando los aportes del neokantismo de la escuela de Marburgo - que intenta hacerse con el contenido de la realidad partiendo de categorías lógicas y conservando el carácter cerrado del sistema-, la posición pretendidamente antagónica a esta, la filosofía de la vida de Simmel — “orientada psicológicamente y con un tono irracionalista" (Adorno, 1991: 75), resignada a un concepto naturalista de lo viviente—, la filosofía de Rickert — “que media entre ambos extremos" y se halla por ello entre la necesidad lógica y la multiplicidad psicológica-, incluso Husserl —quien "ha purificado al idealismo de todo exceso especulativo (...) pero no lo ha hecho explotar" - y Max Scheler — en cuyo pensamiento la fenomenología material se ha replegado dialécticamente sobre sí misma haciendo que de su proyecto ontológico "quede ya sólo la mera metafísica de 
un impulso" (Ibidem: 79)-.

En este itinerario propuesto por el filósofo frankfurtiano aparecen también los nombres de quienes de una u otra manera interpelan de manera especial sus reflexiones, Kierkegaard y Heidegger. La filosofía existencial de Sören Kierkegaard y su dialéctica imparable condujeron, según Adorno, a la desesperación, de allí que la subjetividad solo pudiera salvarse en un salto a la trascendencia. No obstante, la auténtica culminación de este camino encuentra su referente en la figura de Heidegger, quien, al decir adorniano, solo ha sido "capaz de sustraerse a tal consecuencia aceptando una realidad adialéctica por principios e históricamente predialéctica" (Ibidem: 80). En su filosofía también el ser subjetivo ha sido justificado en el salto y la negación dialéctica: se prohíbe toda trascendencia de una fe, pero en su lugar se reconoce una trascendencia hacia el «ser así» en la muerte.

Estas diversas maniobras filosóficas esgrimen cada una a su manera, según expresa Adorno, un trunco frente de lucha que brega por vehiculizar la racionalidad filosófica en cuanto el entendimiento profundo y riguroso de las estructuras del mundo y del sujeto. En este proceso, el discernimiento del andamiaje más íntimo de la realidad ha sido identificado con las conclusiones de la filosofía de Martin Heidegger.

6. La filosofía del autor de Ser y tiempo constituye otro de los flancos contra los que Adorno debate abiertamente. De hecho, en La actualidad de la filosofía el filósofo presta especial atención a la teoría heideggeriana y se extiende sobre algunos de sus puntos que considera especialmente cuestionables. Ello porque, en la concisa reconstrucción histórica elaborada en la conferencia de 1931, Heidegger aparece como la culminación sintética de los diferentes intentos filosóficos del siglo XX. Si bien no todo pensamiento se reconoce necesariamente en cuanto heideggeriano, Adorno entiende que es la filosofía de Heidegger la que ha logrado consolidar la pregunta que domina todo el terreno de la filosofía contemporánea: ante el preguntar óntico y el preguntar ontológico ingenuo, Heidegger configura un preguntar ontológico originario como el verdadero tema de una ontología fundamental.

A partir de ello, la pregunta que se califica de radical, dice el filósofo 
frankfurtiano, es la pregunta por el Ser. En consecuencia, Adorno dedica gran parte de su conferencia a discernir ciertas dimensiones de este hecho. Según expresa, frente al deterioro de la razón legitimadora - tal como la caracteriza Adorno-, Heidegger acude a «lo originario» en tanto una senda de restablecimiento de la relación rota entre racionalidad y realidad. Pues si bien Heidegger admite cierta incomprensibilidad del «Ser», no obstante, afirma que:

el hecho de que vivamos en cada caso ya en cierta comprensión del ser, y que al par el sentido del ser sea embozado en la oscuridad, prueba la fundamental necesidad de reiterar la pregunta que interroga por el sentido del término. (Heidegger, 2007: 13).

En ese sentido, Adorno observa que tal pregunta, erigida en la tarea fundamental de la filosofía contemporánea según el fenomenólogo, yergue su sustancialidad en un supuesto que es preciso explicitar. La pregunta por el Ser, dice Adorno (1991), "da ya por sentado, como algo que posibilita responderla, que el Ser sin más se adecua al pensamiento y le resulta accesible, que se puede formular la pregunta por la idea de lo existente" (74).

Dicho de otro modo, la interrogación cardinal de los esfuerzos filosóficos que moldean la escena contemporánea tiene a su base una identidad en la que es menester detenerse: preguntar por el Ser implica tender un lazo de algún tipo entre él y la razón. Este lazo se construye en las disquisiciones heideggerianas en una identidad que no es explicitada: según Adorno, la reflexión que erige como su pregunta radical aquella que se refiere al Ser experimenta el lenguaje como $\varphi v ́ \sigma \varepsilon l$ y no como $\theta \varepsilon \dot{\varepsilon \varepsilon l . ~}{ }^{7}$

Heidegger ataca la escisión histórica en la que ha devenido lo real, pero la recubre con el aura de «lo auténtico». Con ello, los nuevos proyectos ontológicos entran en contacto con los sistemas idealistas que pretenden

7 Dice Adorno (2005) que "Heidegger tiene para sí que no hay ningún en sí no lingüístico; que el lenguaje, por tanto, está en la verdad, no está en el lenguaje como algo meramente designado por él" (111); de esa manera, no solo ignora el devenir histórico del lenguaje, sino que lo hace al intentar restaurar el poder del nombre - y con él, el de la razón — "a través de un ritual del nombrar" (Ibidem: 111). 
superar (Ibidem: 73). Ese es el sentido de la caracterización heideggeriana del preguntar ontológico en cuanto más originario que el preguntar óntico: cuando Heidegger explica por qué la pregunta por el ser es más originaria que las otras preguntas en las que se ha debatido la filosofía, incurre en una petitio principii, pues

aquello que, en realidad, ésta [la pregunta por el ser] debería demostrar, es decir, la anterioridad del ser con respecto a las regiones particulares del ser, más aún por completo, la anterioridad del ser con respecto al ente particular, se presupone como algo ya existente en el concepto de la originariedad. (Adorno, 2017: 77)

Es decir, Heidegger afirma en su insistencia en la pregunta por el Ser que, de hecho, existe en la actualidad la posibilidad de pensar — en la forma de la pregunta - sobre el Ser. Aun para poner en crisis los modos históricos de hacerlo, afirmar los desaciertos y enmiendas precisos implica sostener que el pensamiento puede vincularse con una estructura tal como la del Ser y apuntalar en ello la pretensión de verdad.

Según Adorno, Heidegger trabaja para sustraerse de la gran amenaza de la fenomenología ontológica, el historicismo. Pero para ello ontologiza el tiempo (Adorno, 1991: 81); así, deshistoriza la relación del pensamiento con el Ser al tratar su historia fuera de la historia y situarla en el epicentro de lo originario:

en este culto al concepto de originariedad misma está contenido, por cierto, el hecho (...) de que la prima philosophia, es decir, lo primero y ancestral, el $\dot{\alpha} \rho \chi \eta \dot{~ e s ~ m a ́ s ~}$ verdadero, mejor y más profundo (...), la superstición de que la verdad no pudo haber sido producida, sino que lo no producido, lo originario, debería ser, por eso mismo, necesariamente también lo más verdadero. (Adorno, 2017: 79).

La relación de la razón filosófica con la verdad se inscribe en el ámbito de la totalidad en la medida que ambos se encuentran y se identifican en la abstracción de un tiempo que no es material, que no está atravesado por las condiciones reales (las condiciones de producción) de lo que está siendo. Heidegger (2007) asevera que: 
el análisis de la historicidad del «ser-ahí» trata de mostrar que este ente no es «temporal» por «estar dentro de la historia», sino que, a la inversa, sólo existe y puede existir históricamente por ser temporal en el fondo de su ser (407).

Afirmaciones de este calibre sostienen lo que Adorno le objeta al autor de Ser y tiempo: él toma al Ser como algo dado y no producido, por ello reflexiona sobre él como si de hecho el Ser «existiera». El Ser opera en la filosofía heideggeriana como lo hacía en las antiguas filosofías que pretende superar; esto es, como una totalidad que condice las posibilidades de la razón. En lugar de debatir acerca de la factibilidad de cierta conmensurabilidad entre una y otra esfera, la pregunta por el Ser habilita otra vez, ${ }^{8}$ según Adorno, el horizonte de la totalidad como vehículo del filosofar.

7. Así entonces, la exposición de la red de vertientes teóricas llevada a cabo en La actualidad de la filosofía, aunque pareciera mostrar una multiplicidad de líneas teóricas diversas entre las que destaca por mucho la filosofía heideggeriana, concreta no obstante las distintas maneras en que el idealismo había entrado en crisis y, con ello, las distintas formas de referir la crisis de la pretensión filosófica de totalidad.

Todas las expresiones del pensamiento alemán contemporáneo analizadas por Adorno manifiestan según él no solo la impotencia del pensamiento filosófico para adecuarse al Ser sino, aún más, la impotencia de la idea de Ser en cuanto principio formal. Atento a las condiciones históricas planteadas por el inicio de siglo, Adorno asevera enfáticamente que "la adecuación del pensamiento al Ser como totalidad se ha desintegrado" (Adorno, 1991: 74).

El autor de La actualidad de la filosofía sostiene que el estado del pensamiento filosófico circundante revela que la idea de existencia (la pregunta por el Ser) ya no resulta planteable en cuanto idea en la medida en que la figura sobre la que se levanta — esto es, la idea de totalidad en cuanto una "clara transparencia sobre una realidad cerrada"- resulta ya

8 Como en el planteo materialista de Georg Lukács descrito previamente. 
impotente. En la medida en que la historia de Occidente ha patentizado una disgregación constante y paulatina sobre las distintas esferas constitutivas de la vida moderna, Adorno afirma que esa realidad no admite ya ser medida ni explicada desde una categoría que le resulta completamente ajena: la totalidad no constituye un índice de la realidad, sino, una expresión de la razón que se escinde de ella.

En consecuencia, aquellos proyectos filosóficos - especialmente, claro está, el heideggeriano-, los cuales asumen la pregunta por el Ser como el tono que marca el ritmo de sus investigaciones, lejos están de establecer una relación íntima con la realidad y su verdad. Por el contrario, revelan más bien el modo en que la idea de Ser se ha vuelto impotente en filosofía y se ha consolidado como "no más que un principio formal cuya arcaica dignidad ayuda a disfrazar contenidos arbitrarios" (Ibidem: 74).

Las disquisiciones en relación al carácter contradictorio de la racionalidad moderna de principios de siglo XX constituyen un escenario de suma relevancia para comprender el desarrollo de esta crítica a la razón moderna ejecutada por Theodor Adorno. Entre las denuncias de la instrumentalización de la razón, su ordenamiento teleológico y la pérdida del sentido inmanente del mundo, el pensador frankfurtiano diagrama su perspectiva teórica. Es esa trama la que torna comprensibles sus debates sobre la figura de la totalidad como epicentro problemático del pensamiento contemporáneo. Asimismo, desde este ángulo puede justificarse la importancia que asume en La actualidad de la filosofía el recorrido por diversas expresiones del pensamiento alemán de la primera mitad del siglo XX.

El señalamiento de una dialéctica compleja tendida entre en el movimiento de ensanchamiento y el de estrechamiento constituye el horizonte propicio para la elaboración del diagnóstico de época ejecutado por Adorno. La puesta en cuestión de la práctica filosófica y su capacidad crítico-analítica de la realidad — emanada de este mismo señalamiento - conduce al filósofo no solo a empuñar como tarea filosófica primordial la crítica de la racionalidad moderna, sino, aún más, a configurar esa crítica en base al despliegue de esa racionalidad en el escenario de la historia filosófica. De allí que en la 
conferencia de 1931 cobre especial relevancia la confección de un mapa de pensamiento atravesado por la mirada micrológica y la denuncia al talante teleológico-instrumental de la racionalidad moderna.

Las distintas expresiones filosóficas indagadas en La actualidad de la filosofía se concentran, según su autor, o bien en la pregunta por el Ser, o bien en la pregunta por la validez de la pregunta por el Ser. Con ello condenan a muerte al pensamiento filosófico en la medida en que "la filosofía que a tal fin se expende hoy no sirve para otra cosa que para velar la realidad y eternizar su situación actual" (Ibidem: 73). Aquí cobra sentido el periplo sucinto a través del panorama filosófico alemán enunciado en esta conferencia: él tiene como objetivo poner de manifiesto dos cosas de suma relevancia a la hora de diagramar la particular crítica adorniana a la racionalidad filosófica de la modernidad.

En primer lugar, el recorrido por las diversas expresiones filosóficas le permite a Adorno poner de manifiesto que el problema radical que enfrenta la filosofía en la primera mitad del siglo XX es su propia condición de moribunda. Ante la insuficiencia para suturar la escisión entre el sujeto y el objeto, ante su incapacidad para transformar la situación contemporánea, la filosofía habita una instancia liminar; ella se encuentra suspendida en la frontera que separa su vitalidad de la muerte. En ese sentido, la racionalidad filosófica que en este contexto se pretenda crítica no puede menos que inquietarse y urdir una estrategia determinante de la persistencia o la modificación de tal situación.

En segunda instancia, Adorno cifra tal mortandad filosófica en la impotencia consecuente del modo en que en ella opera el «tiempo». Abocadas a discernir los vaivenes que han moldeado lo relativo al «Ser», las diversas teorías filosóficas por él mencionadas han vehiculizado la temporalidad en un sentido constitutivo olvidando que ella no es una totalidad que atraviesa otra totalidad —ladel Ser-. El tiempo, lejos de concebirse en cuanto «temporalidad»—con la abstracciónquedenotaelsufijoquelasustantiva — hadeconcretarseen «historia», una expresión más fiel a la materialidad contradictoria que piensa Adorno. 
La invectiva dirigida a los filósofos abordados por el frankfurtiano deja en claro cómo se concreta la relación del ejercicio filosófico con la historia: la condena a muerte del pensamiento filosófico se ejecuta, como se dijo, cuando ella eterniza la situación actual (Ibidem: 73). Resuena, sin duda, el dictum conclusivo de las Tesis sobre Feuerbach escritas por Marx en la primavera de $1845^{9}$. Cuando Adorno denuncia la pregunta por el ser al sostener que ella solidifica la situación actual en tanto que la recubre de juicios que la opacan, afirma subterráneamente que la función temporal de la filosofía no consiste en reproducir la historia, sino en transformarla. ${ }^{10}$ Es que, tal como plantea, las reflexiones que insisten en asir el orden de lo existente según la disposición de la totalidad, es decir, las filosofías que persisten en su intento de asegurar la realidad mediante su identificación con el Ser, siguen reproduciendo los intentos idealistas que ya Marx detectó.

Desde esta perspectiva, la auténtica empresa de las líneas teóricas analizadas por Adorno en La actualidad de la filosofía consiste en la «liquidación de la filosofía» ya que, lejos de abrir instancias más auténticas para el Ser y el Pensar, ellas destinan sus esfuerzos a consumar el deceso filosófico.

Dos vertientes aparentemente opuestas, la del neopositivismo y la del existencialismo fenomenológico, convergen de manera aparentemente insólita. Ambas conminan al trabajo filosófico a la muerte. Por un lado, con la ayuda de la crítica epistemológica, la lógica más avanzada en que devino la filosofía kantiana ha restringido todo conocimiento a los límites de una experiencia comprobable, con lo cual, "la filosofía se convierte exclusivamente en instancia de ordenación y control de las ciencias particulares, sin poder permitirse añadir nada sustancial" (Ibidem: 84). Por el otro, y en cuanto

9 Aludimos, claro, al célebre pasaje según el cual "[XI] Los filósofos no han hecho más que interpretar de diversos modos el mundo, pero de lo que se trata es de transformarlo" (Marx, 2014: 61).

10 Por supuesto que esto no denota ningún tipo de intervención activa a manos de un sujeto histórico de lo político. Adorno nunca promovió un programa político propositivo a partir del cual transformar la realidad en tales o cuales términos. En su caso, se trata más bien de comprender la dimensión activa del pensamiento desde una perspectiva crítica. 
complemento de lo primero, a ese ideal de filosofía científica le corresponde "un concepto de poesía filosófica cuya arbitrariedad respecto a la verdad sólo se ve superada por su inferioridad estética y por su lejanía de cuanto sea arte" (Ibidem: 84).

Así, la cartografía que efectúa Adorno de las distintas vertientes teóricas determinantes de la actividad filosófica de Alemania en las primeras décadas del siglo XX muestra que el contradictorio ritmo a dos tiempos de la modernidad europea encuentra algunas de sus aristas definitorias en una relación erosionada con la verdad y en las búsquedas a ella asociada. En las coordenadas establecidas por este cuadro de época se tornan comprensibles, en consecuencia, las afirmaciones de Lukács y Horkheimer en torno a la situación de la razón.

El diagnóstico de Adorno apunta hacia conceptos de «modernidad» y «razón» que indican la estrategia de resquebrajamiento de los fundamentos míticos del mundo y la correspondiente edificación racional de los pilares de la realidad tanto como al proceso de enmohecimiento de esos pilares. En la medida que se comprende que «modernidad» es tanto el nombre del proceso de diferenciación de la razón mediante el cual se arriba a la institucionalización de distintos ámbitos (tales como la ciencia, el arte y la filosofía) como, en simultáneo, también el nombre que designa el devenir de esa diferenciación progresiva bajo el signo común de un debilitamiento esclerótico; se comprende entonces el problema de la razón señalado por el pensador frankfurtiano.

\section{REFERENCIAS}

Adorno, Th. (1991). “Actualidad de la Filosofía”. En Actualidad de la filosofía (J. L. Arantegui Tamayo, Traductor) (73-102.). Barcelona: Paidós. (2004). Teoría estética (J. Navarro Pérez, Traductor). Madrid: Akal. (2005). Dialéctica negativa. La jerga de la autenticidad (A. Brotons Muñoz, Traductor). Madrid: Akal.

(2006). Minima moralia. Reflexiones desde la vida dañada (J. Chamorro Mielke, Traductor). Madrid: Akal. 
(2013). Introducción a la dialéctica (M. Dimópulos, Traductora). Buenos Aires: Eterna Cadencia.

(2017). Ontología y dialéctica (L. S. Carugati, Traductora). Ciudad Autónoma de Buenos Aires: Eterna Cadencia.

Benjamin, W. (2005). Libro de los Pasajes (L. Fernández Castañeda, I. Herrera y F. Guerrero, Traductores.). Madrid: Akal.

(2012). Origen del Trauerspiel alemán (C. Pivetta, Traductora). Buenos Aires: Gorla.

Buck-Morss, S. (2011). Origen de la dialéctica negativa. Theodor W. Adorno,

Walter Benjamin y el Instituto de Frankfurt (N. Rabotnikof Maskivker, Traductora). Buenos Aires: Eterna Cadencia.

Forster, R. (2014). La travesía del abismo. Mal y Modernidad en Walter Benjamin. Ciudad Autónoma de Buenos Aires: Fondo de Cultura Económica.

Freud, S. (2007). El malestar en la cultura (L. López-Ballesteros, Traductor). Barcelona: Biblioteca Nueva.

Hegel, G. W. E. (2015). Fenomenología del espiritu (W. Roces, Traductor). Ciudad Autónoma de Buenos Aires: Fondo de Cultura Económica.

Heidegger, M. (2007). El ser y el tiempo (J. Gaos, Traductor). México: Fondo de Cultura Económica.

Horkheimer, M. (2007). Crítica de la razón instrumental (H. A. Murena y D. J. Vogelmann, Traductores). La Plata: Terramar.

Kant, I. (2010). Contestación a la pregunta: ¿Qué es la Ilustración? (R. R. Aramayo, Traductor). En Kant III (317-325). Madrid: Gredos.

Lukács, G. (2013). Historia y conciencia de clase. Estudios de dialéctica marxista (M. Sacristán, Traductor). Ciudad Autónoma de Buenos Aires: Razón y Revolución.

Marx, K. (2014). “Tesis sobre Feuerbach”. En Antología (P. Scaron, Traductor; H. Tarcus, selección, introducción y notas) (59-61). Buenos Aires: Siglo Veintiuno. 
Said, E. (2015). “Teoría Viajera" (R. Zamorano, Traductor). En Cuadernos de teoría y crítica: Teorías viajeras (R. Rodríguez Freire, Editor). Viña del Mar: Pontificia Universidad Católica de Valparaíso.

Hofmannsthal, H. v. (1990). La carta de Lord Chandos. En La carta de Lord Chandos y algunos poemas (J. García Terrés, Traductor y Editor). México: Fondo de Cultura Económica.

Simmel, G. (2011). El conflicto de la cultura moderna (C. Astrada, Traductor). Colección Mínima. Córdoba: Universidad Nacional de Córdoba, Encuentro Grupo Editor.

Spengler, O. (1993). La decadencia de Occidente (M. G. Morente, Traductor). Barcelona: Planeta.

Weber, M. (2001). La ciencia como profesión. La politica como profesión (J. Abellán, Traductor). Colección Austral. Madrid: Espasa Calpe.

Wellmer, A. (2013). Lineas de fuga de la modernidad (P. Storandt Diller, Traductor). Buenos Aires: Fondo de Cultura Económica; Universidad Autónoma Metropolitana.

Wittgenstein, L. (2009). Tractatus logico-philosophicus. Sobre la certeza (J. Muñoz Veiga e I. Reguera Pérez, Traductores). Madrid: Gredos. 